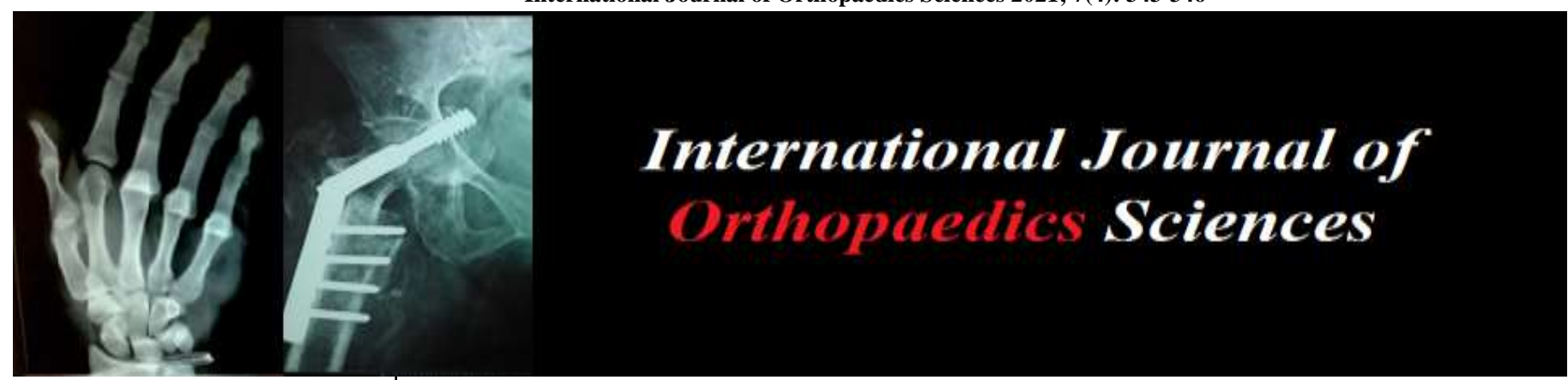

E-ISSN: 2395-1958

P-ISSN: 2706-6630

IJOS 2021; 7(4): 343-346

(C) $2021 \mathrm{IJOS}$

www.orthopaper.com

Received: 23-08-2021

Accepted: 26-09-2021

Dr. Kalom Jamoh

Department of Orthopedic

ESIC-PGIMSR, Basaidarapur,

New Delhi, India

DR. Gyneshwar Tonk

Department of Orthopedic.

LLRM Medical College, Meerut,

Uttar Pradesh, India

Dr. Sumit Agarwal

Department of Orthopedic.

LLRM Medical College, Meerut,

Uttar Pradesh, India

\section{A dilemma for management of third fragment of shaft femur fracture with closed intramedullary nailing: A retrospective study}

\section{Dr. Kalom Jamoh, Dr. Gyneshwar Tonk and Dr. Sumit Agarwal}

DOI: https://doi.org/10.22271/ortho.2021.v7.i4e.2905

Abstract

Background: Aim of this study was to report the union rate of fracture shaft femur with third fragments after closed intramedullary nailing.

Methods: Sixty patients were analyzed retrospectively, AO/ASIF classification was done. Fractures were treated with closed intramedullary nail. Followed up in OPD until fracture united.

Results: Mean union time was 30 weeks which is longer than average time period for union of shaft femur fracture. There were two cases of non-union.

Conclusion: Use of closed intramedullary nail technique for treatment of shaft femur fracture with third fragments has predictable union rate and union of bone is related to the displacement of third fragments and irrespective of size of fragment.

Keywords: Closed IM nail, shaft femur fracture with third fragment, displacement, size of fragment

\section{Introduction}

Shaft femur fractures with third fragments account for $10-34 \%$ of all shaft femur fractures ${ }^{[1]}$. Close reduction with intramedullary nailing technique is the commonly performed surgery for femoral shaft fracture ${ }^{[2]}$. However there is a dilemma to manage the third fragment after closed IM nailing whether to keep it untouched or open the fracture site and fix the fragment with SS- wire or unicortical plate. But we know that opening the fracture site can leads to complications like infection, blood loss and longer duration of surgery etc ${ }^{[3,4]}$. In order to avoid such complications of open reduction and fixation of third fragments, we had to study 60 cases of shaft femur fracture with third fragments managed by closed reduction with IM nailing retrospectively.

\section{Methodology}

This study was hospital based and conducted in the Department of Orthopedic at LLRM Medical College and S.V.B.P Hospital Meerut, Uttar Pradesh. The duration of the study was from June 2017 to February 2021 on an OPD basis. There were sixty cases of femoral shaft fracture with third fragments managed by closed reduction with IM nailing which were analysed retrospectively using discharged documentation and pre-operative and post-operative radiograph without control group. Patients with pathological fracture, open fracture and ipsilateral proximal and distal femur were not included.

\section{Operative Procedure}

Patient was positioned on the fracture table with traction after spinal anaesthesia, scrubbing, painting and draping done in aseptic condition. Closed reduction performed and guide wire were inserted and position of guide wire were confirmed by fluoroscopy image. Reaming was done only for the proximal fragment and the appropriate nail was inserted and locked.

\section{Method of assessment}

A fragment displacement was measured by determining the perpendicular distance of the proximal or distal end of the fragment to the nearest cortex of the shaft femur and the size of the third fragment was determine by measuring its longitudinal length using plain radiograph post-operatively.

\section{Dr. Kalom Jamoh}

Department of Orthopedic.

ESIC-PGIMSR, Basaidarapur

New Delhi, India 
Bone union was defined as bony continuity in 3 or more of the 4 cortical surfaces as observed in X-Ray of shaft femur $\mathrm{AP}$ and Lateral views. Non-union was defined as no sign of union since the last three months after the period of one and half years.

\section{Results}

There were sixty patients ( 54 males, 6 females); the median age was 23 years (range: 18 to 70$)$. The majority $(62 \%, 37$ patients) of fractures were the result of road traffic accidents; followed by fall from height $(18 \%, 11$ patients) were the common mechanism of injury. The right shaft femur was involved in 52 cases $(87 \%)$. Table- 1 .

Overall 60 fractures were treated with closed locked IM nailing, mean union time was 30 weeks (range: 20-50 weeks) which is much longer than the average time period of fracture shaft femur without third fragment.

58 cases $(96.7 \%)$ got united without any complications, but there were 2 cases $(3.3 \%)$ which landed into non-union which was managed by autologous bone grafting.

\section{Discussion}

Intramedullary nailing is the ideal treatment for fracture shaft femur which will preserve the biology of soft tissue and will not interfere with the hematoma formation in fracture site ${ }^{[6]}$. But for fracture shaft femur with third fragment (AO-32.B \& C) there is a dilemma, whether to fix or not, the third fragment after closed IM nailing, which is very much not described in the literature too.
In our setup closed IM nailing was performed in sixty cases of fracture shaft femur with a third fragment, where only proximal reaming was done ${ }^{[7,8]}$. Hypothesis being - 1 . Reaming only proximal fragments- bone marrow filled the void created by displacement of the third fragment and acted as graft. 2. Reaming through the fracture site will disrupt the periosteum and microvasculature which make the third fragment more displaced and rotated. (Fig-4).

Fifty eight cases $(96.7 \%)$ out of sixty cases got united with mean union time of 30 weeks (range: 20-50 weeks) which was much longer duration in comparison to mean union time of fracture shaft femur without third fragment. Two cases $(3.3 \%)$ with displacement of more than $1 \mathrm{~cm}$ landed into nonunion which was managed by autologous bone graft. Lin et al. [9] also found in their study that displacement of more than $1 \mathrm{~cm}$ has a higher chance of non-union.

Recently J.R. Lee et al. ${ }^{[10]}$ study concluded that non-union were found to develop where third fragments were $8 \mathrm{~cm}$ or longer and displacement of $1 \mathrm{~cm}$ or more but in our study it is observed that size of fragment has no role in non- union.

Giovanni Vicenti et al. ${ }^{[11]}$ study concluded that the third fragment size is the leading parameter to influence the fracture healing within or in more than six months, which is comparable to our study.

Kempf et al. ${ }^{[5]}$ also found in their study that risk of infection and non- union is low which is comparable to our study.

Daniel Layon et al. ${ }^{[12]}$ concluded that the presence of flipped intercalary segments may not require different surgical management than the treatment of conventional femoral shaft fractures.

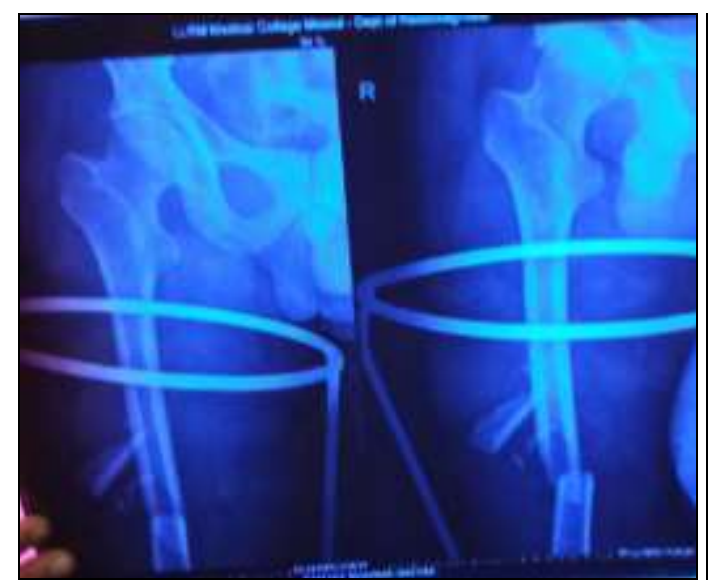

Pre-Op

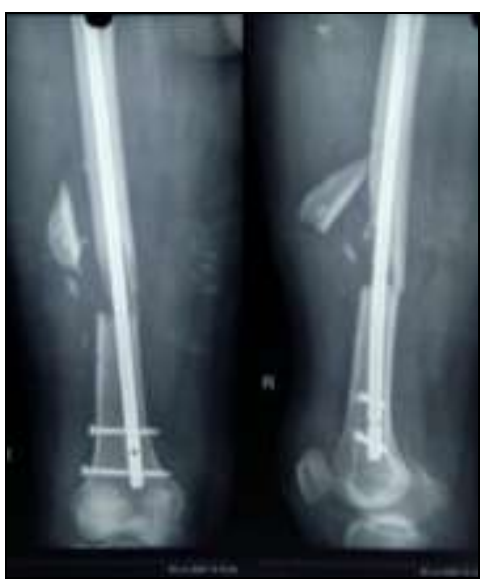

Immediate Post-Op

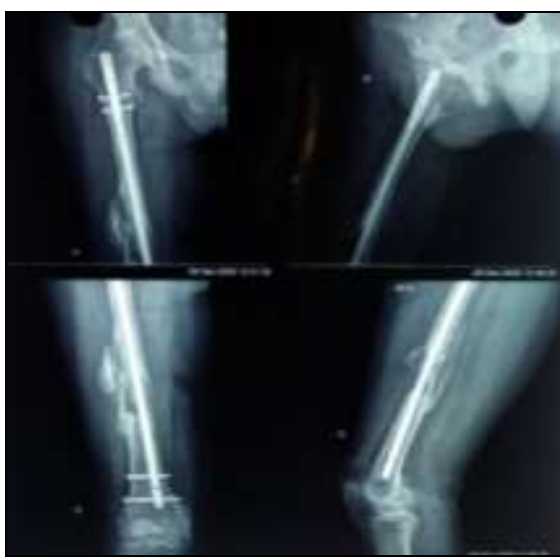

AT 3 months

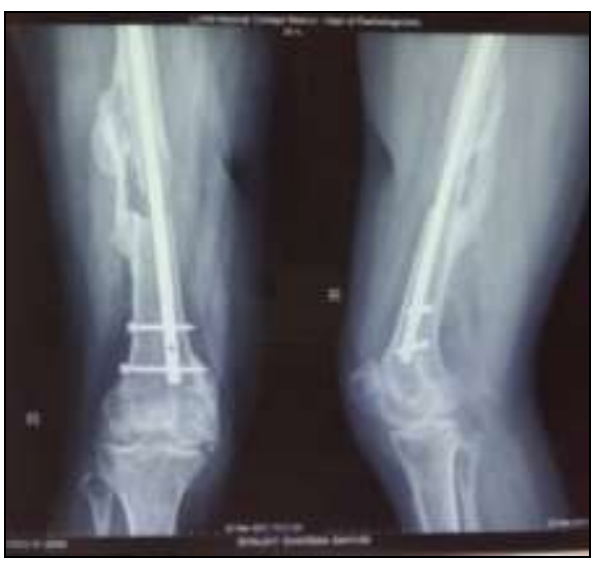

AT 9 Months

Fig 2. 
Case-2 Open Reduction with SS Wire Augmentation

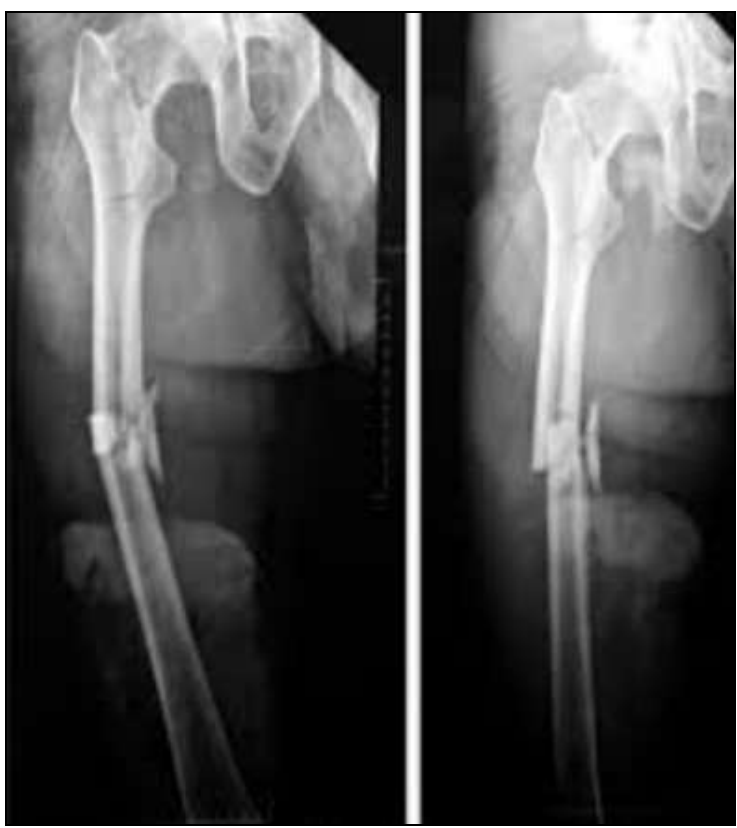

Pre-op

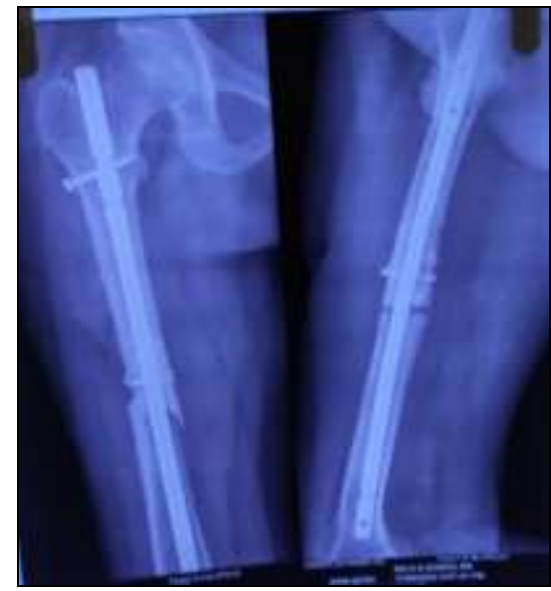

At 3 months

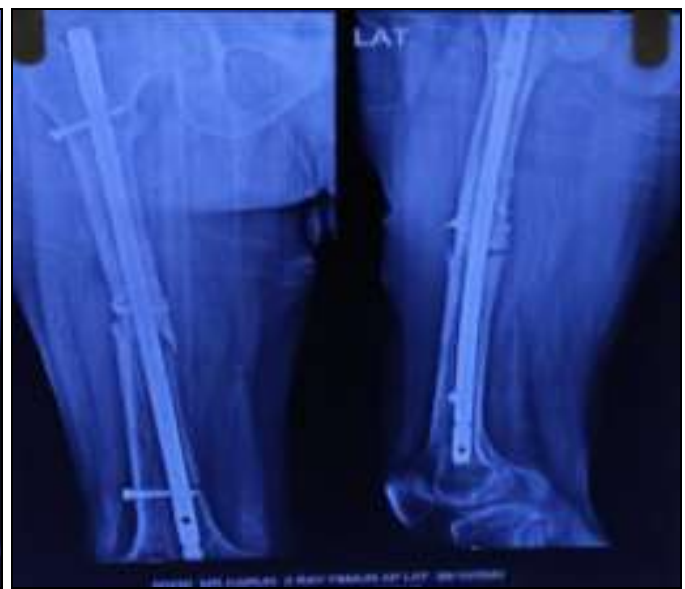

At 9 months without callous formation

Table 1: Population attributes

\begin{tabular}{|l|l|}
\hline \multicolumn{1}{|c|}{ Population attributes } & \multicolumn{1}{c|}{ Value } \\
\hline Number of patients & 60 \\
\hline Males & $54(90 \%)$ \\
\hline Females & $6(10 \%)$ \\
\hline Median age & $23(18-70)$ \\
\hline Right Side femur fracture & $52(87 \%)$ \\
\hline Left side femur fracture & $8(13 \%)$ \\
\hline \multicolumn{1}{|c|}{ Mechanism of injury } & \\
\hline Road traffic accident & $37(62 \%)$ \\
\hline Fall from height & $11(18 \%)$ \\
\hline Others & $12(20 \%)$ \\
\hline
\end{tabular}




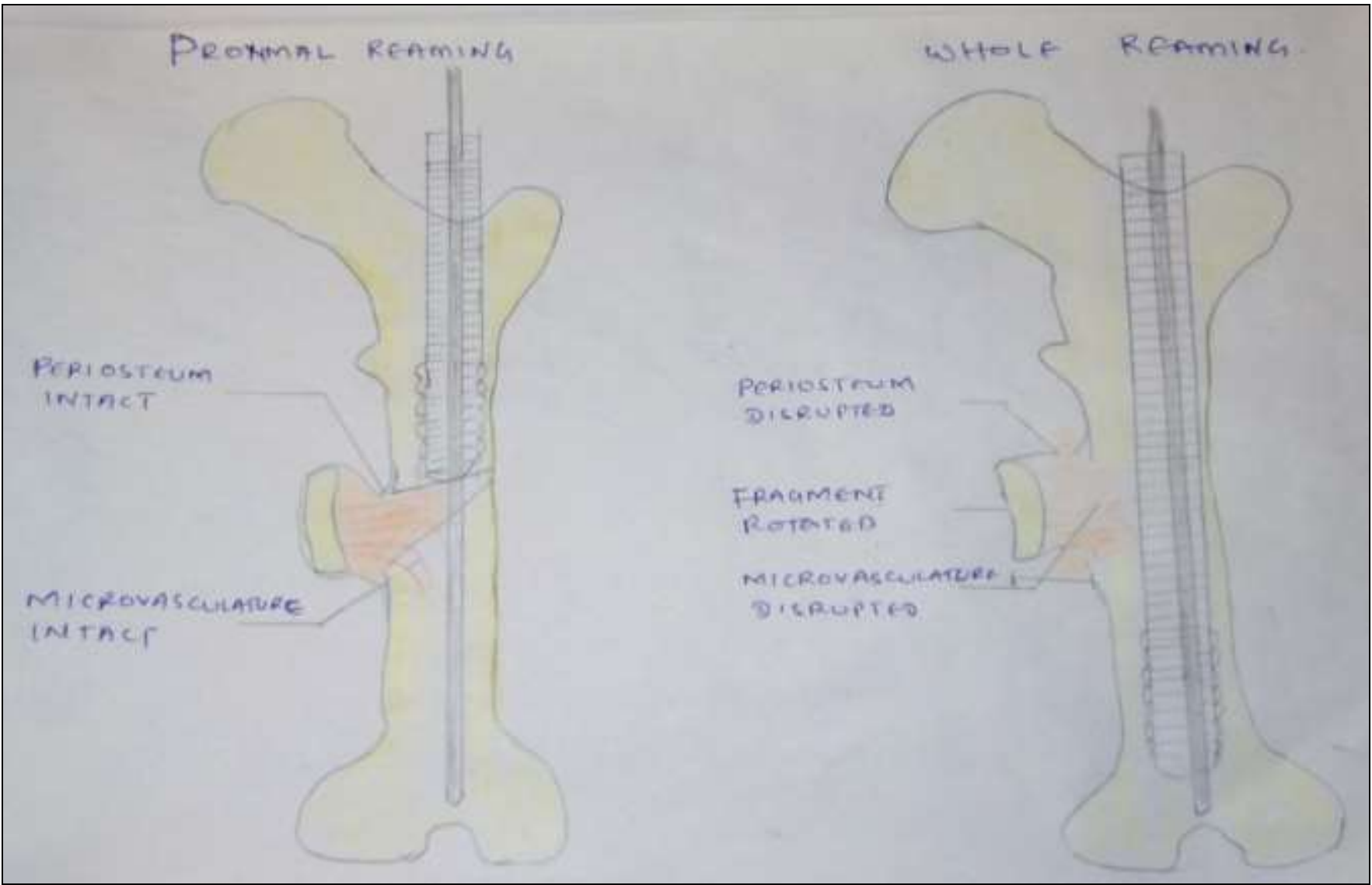

Fig 4: Diagram showing how reaming affect the third fragment

\section{Conclusion}

Closed locked IM nailing will be the ideal for management of fracture shaft femur with third fragment with excellent union rate and less risk of infection. Non-union rate may be directly related to displacement of third fragment but not the size of fragment.

\section{References}

1. Salminen ST, Pihlajamaki HK, Avikainene VJ, Bostman OM. Population based epidemiologic and morphologic study of femoral shaft fractures. Clin OrthopRelat Res 2000;372:241-9.

2. Wolinsky PR, McCarty E, Shyr Y, et al. Reamed intramedullary nailing of the femur: 551 cases. J Trauma 1999;46:392-9.

3. Bostman O, Varjonen L, Vainionpaa S, Majola A, Rokkanen P. Incidence of local complications after intramedullary nailing and after plate fixation of femoral shaft fractures. J Trauma 1989;29:639-45.

4. Bellabarba C, Ricci WM, Bolhofner BR. Results of indirect reduction and plating of femoral shaft non-unions after intramedullary nailing. J Orthop Trauma 2001;15:254-63.

5. Kempf I, Grosse A, Beck G. Closed intramedullary nailing: Its application to comminuted fractures of the femur. J Bone Joint Surg Am 1985;67:709-20.

6. Wiss DA, Fleming CH, Matta JM, Clark D. Comminuted and rotationally unstable fractures of the femur treated with an interlocking nail. Clin Orthop Relat Res 1986;212:35-47.

7. Claes L, Eckert-Hubner K, Augat P. The effect of mechanical stability on local vascularization and tissue differentiation in callus healing. $\mathbf{J}$ Orthop Res 2002;20:1099-105.
8. Lienau J, Schell H, Duda GN, Seebeck P, Muchow S, Bail HJ. Initial vascularization and tissue differentiation are influenced by fixation stability. J Orthop Res 2005;23:639-45.

9. Lin SJ, Chen CL, Peng KT, Hsu WH. Effect of fragmentary displacement and morphology in the treatment of comminuted femoral shaft fractures with an intramedullary nail. Injury 2014;45:752-6.

10. Lee JR et al. Effect of thirds fragment size and displacement on non-union of femoral shaft fractures after interlocking nail. Orthopedic and traumatology: surgery \& research 2016;102:175-181.

11. Giovanni vinceti et al. the impact of the third fragment features on the healing of femoral shaft fractures managed with intramedullary nailing: a radiological study. International orthopedics 2019;43:193-200.

12. Daniel Layon et al. The flipped third fragment in femoral shaft fractures: A reason for open reduction? Published: 2020, 22.

DOI: https://doi.org/10.1016/j.injury.2020.09.049 